\title{
Correlation of Pain Intensity and Level of Disability with the Socio-demographic Characteristics in Patients with Chronic Mechanical Low Back Pain
}

\author{
Sami Salman Shihab ${ }^{1}$, Eman Qasim Khider ${ }^{2}$ \\ ${ }^{1}$ Rheumatology Unit, Department of Medicine, College of Medicine, University of Baghdad, Baghdad, Iraq \\ ${ }^{2}$ Rheumatology Unit, Baghdad Teaching Hospital, Baghdad, Iraq
}

Email address:

Dr.emanqassim@gmail.com (E. Q. Khedir)

\section{To cite this article:}

Sami Salman Shihab, Eman Qasim Khider. Correlation of Pain Intensity and Level of Disability with the Socio-demographic Characteristics in Patients with Chronic Mechanical Low Back Pain. International Journal of Pharmacy and Chemistry. Vol. 7, No. 4, 2021 , pp. 58-70. doi: $10.11648 /$ j.ijpc.20210704.12

Received: May 29, 2021; Accepted: July 5, 2021; Published: July 16, 2021

\begin{abstract}
Background: Mechanical low back pains are pains occurred due to an anatomic or functional abnormality in the spine that is not associated with inflammatory or neoplastic disease. Socio-demographic characteristics for chronic low back pain are important cause of disability. Disability can be defined as a restriction or lack of ability to perform an activity in the manner or within the range considered normal for a human being. Subsequently, this interferes with quality of life and work performance with subsequent burden on a family and community. This study aims to describe the socio-demographic characteristics of patients with chronic mechanical low back pain and asses its relationship with pain intensity and level of disability. Patients with chronic mechanical low back pain who met inclusion criteria participated in this cross-sectional study. All demographic data were taken, and the patients have been classified according to their academic level, their social class according to national readership survey, assess pain severity according to visual analogue scale, and functional disability according to Quebec back pain disability scale. A significant association were found between the level of disability in chronic back pain and each of age, gender, BMI, educational level, residency place, job and type of work and associated comorbid illnesses. Chronic LBP intensity was associated with female gender, primary school education, manual workers and housewives, higher BMI, and disease duration of more than five years.
\end{abstract}

Keywords: Chronic Mechanical Low Back Pain, Socio-demographic Data, Pain Intensity, Disability Level

\section{Introduction}

\subsection{Chronic Mechanical Low Back Pain}

\subsubsection{Definition and Epidemiology}

Low back pain (LBP) is defined as "pain between the costal margins and inferior gluteal folds and is usually accompanied by painful limitation of movement. It is often influenced by posture and physical activities in most cases" [1].

Mechanical low back Pain (MLBP) is low back pain occurred because of a functional or anatomic abnormality in the spine that is not associated with inflammatory or neoplastic disease [2]. MLBP commonly increases with physical activity and upright posture and tends to be relieved by rest. MLBP accounts more than $95 \%$ of LBP, and degenerative change in the lumbar spine is the most common cause of MLBP [2]. Back pain can be classified according to the duration into a. Acute back pain: less than 6 weeks. b. Sub-acute back pain: between 6 and 12 weeks. c. Chronic back pain: more than 12 weeks [3].

The clinical course is benign for most of the patients, with $95 \%$ of those afflicted recovering within a few months of onset. However, some of them will develop chronic low back pain [1]. Chronic MLBP is a one of leading cause of morbidity and incapacity, being second only to headache in the scale of pain disorders [4].

Chronic MLBP is prevalent in many countries and is associated with loss of quality of life and considerable financial costs [5]. In the United States, for example, chronic mechanical LBP is the fifth most common reason for all 
physician visits $[6,7]$. Patients with chronic MLBP experience a massive disruption in their physical, social, mental, and occupational function, or increase in the level of pain [8].

Occupation-related factors considered the most significant risks associated with chronic mechanical LBP [9]. For instance, chronic mechanical LBP is the most common musculoskeletal problem in the workplace, and it is the main cause of work- related disability [10]. Certainly, this problem is associated with major costs in terms of worker disability and absenteeism [10]. Chronic mechanical LBP, for example, causes approximately $40 \%$ of sick absences from workplaces making it the second most common reason of work place absenteeism after the common cold [11].

Chronic MLBP is widespread in many developed countries with prevalence rates of $39 \%$ being reported in the general population in these societies [12]. WHO statistics indicate the increased prevalence rate of low back pain among the various social class [13].

\subsubsection{Risk Factors of Mechanical Low Back Pain}

Mechanical LBP is not a specific disease but rather a complaint that may be caused by many underlying problems of variable levels of seriousness [14]. MLBP can be classified as occupational, individual, or psychosocial factors [15]. Recently bio-mechanical models and genetic factors have contributed to understand the progress of back disorders that present as back pain [15].

Risk factors for developing chronic MLBP could be modifiable and non-modifiable. The non- modifiable factors include age, gender, prior history of LBP and major scoliosis, while the modifiable factors include obesity, sedentary lifestyle, smoking, parity, and drug dependence. Other modifiable factors are related to the occupation including poor posturing, twisting, bending, prolonged sitting, stooping, and lifting of heavy loads, sedentary work, job dissatisfaction, and psychological factors such as somatization disorder, depression, and anxiety [16]. Researchers have concentrated on both medical and non-medical factors for chronic MLBP such as socio-demographic factors because of its multifactorial nature [17].

\subsubsection{Clinical Features}

Mechanical LBP is usually nonspecific pain for $\geq 3$ month that aggravated by activity and partially improved by rest associated with morning stiffness less than 30 minutes not associated with constitutional symptoms with or without radiation to lower limbs $[18,19]$. The radiating back pain into the lower extremities suggest pseudo-claudication (neurogenic claudication) secondary to sciatica or spinal stenosis. The nature of pain is often shooting and sharp in nature, sometimes associated with sensory and/or motor deficits [20]. The pain is arises from the spines, intervertebral disks, or surrounding soft tissues which is caused by functional or an anatomic abnormality rather than inflammatory or neoplastic disease [21]. The most common cause of mechanical LBP is degenerative change in the lumbar spine [22]. Other common problems include spinal stenosis and disk herniation [23].
Typical physical findings are nonspecific, including paravertebral muscle spasms, muscular trigger points tenderness, tight hamstring muscles, restricted range of motion of the spine, aggravation of symptoms on flexion or extension and straight leg raising tests [24, 25]. In addition to a limited neurological examination focused on sensory, motor function and reflexes in the lower half of the body [26].

\subsection{Disability in Chronic Mechanical Low Back Pain}

Disability refers to "a restriction or lack of ability to perform an activity in the manner or within the range considered normal for a human being. Disability is a core issue in CLBP affecting physical performance and consequently work productivity" [27]. CLBP is leading cause of disability interferes with work performance and quality of life [28]. It is particularly important being responsible for completely disturbing patients' daily activities with subsequent burden on a family and community bases [29].

The impact of CLBP is strongly related to a patient's functional status such as sitting, standing, walking, getting dressed and cleaning. Physical and functional disabilities are concern in health care. Therefore, its assessment is widely accepted [30].

CLBP may cause more disability and negative impact on quality of life, especially in people who are suffering from physical diseases and concurrent mental illnesses [31]. The most common symptoms of LBP are pain and disability. Moreover, it has been suggested recently that many patients with CLBP have widespread pain [32, 33]. In general, disability from low back pain is highest in working age groups $[34,35]$.

\subsection{Correlation of Socio-demographic Character with Chronic Low Back Pain Disability}

Studies have found that the prevalence and intensity of back pain is associated with aging, female gender, as well as occupational and psychosocial factors [36]. In developed countries, modifiable determinants of back pain include obesity, smoking, lack of physical activities and depression. The studies have demonstrated that men older than 40 years with back pain have more negative impact on quality of life [36]. They provide evidence of inverse association between back pain and socioeconomic factors such as older age, education and higher income [36].

\subsection{Aim of the Study}

The aim of this study is to describe the socio-demographic characteristics of patients with chronic MLBP and examine its relationship with pain intensity and disability status.

\section{Patients and Methods}

\subsection{Study Design and Setting}

A cross sectional study was conducted at Rheumatology Unit of Baghdad Teaching Hospital / Medical City from November 
2018 to April 2019, after approval of the study protocol by Committee of the Iraqi Board of Medical Specializations.

\subsection{Patients Selection}

Three hundred patients with chronic MLBP who attended the Rheumatology Unit in Baghdad Teaching Hospital and met inclusion criteria were recruited and asked to participate in the study after obtaining their informed consent.

\subsubsection{Inclusion Criteria}

Patients older than 18 years who had symptoms of chronic mechanical low back pain for more than 3 months duration were included. the patients diagnosed as MLBP which was proven by history, physical examination, and imaging modalities (X-ray and/or MRI).

\subsubsection{Exclusion Criteria}

Patients with one or more of the following criteria were excluded from the study:

a) Congenital disease of lumbar spine

b) Evidence of malignancy

c) Infectious and inflammatory disease

d) Patients with pregnancy

e) Suspicion of cauda-equina syndrome, or LBP surgical emergencies

f) Recent major trauma and fracture, patients who were severely ill and chair bounded, or unable to comprehend questions were excluded.

\subsection{Data Collection}

Data were collected using a data collection sheet containing a questionnaire (Appendix I).

The questionnaire prepared in three sections:

\subsubsection{Section $A$}

Focused on socio-demographic information including age, gender, marital status (single, married, divorced, widow), residency (rural, urban), educational level (illiterate, read and write, primary, secondary, college, higher education), smoking status (smoker, non-smoker, passive, ex-smoker), history of chronic illnesses (hypertension HT, diabetes mellitus DM, Ischemic heart disease IHD, etc.), employment status (employed, not employed), Type of work (manual, non- manual, house wife), and social class according to National Readership Survey (NRS) to (A, B, C1, C2, D, E) (Appendix II).

Anthropometric measurements included:

1. Height which was measured in centimetres to the nearest five millimetres in standing position, shoes removed with head supported against the wall.

2. Weight which was measured by kilogram $(\mathrm{kg})$, the subject in heavy clothes and shoes were removed. Body mass index (BMI) was calculated by dividing weight in kilograms on height in squared meters $\left(\mathrm{m}^{2}\right)$. Subjects were divided according to BMI into four categories [37]:

a. Underweight $<18.5 \mathrm{~kg} / \mathrm{m}^{2}$.

b. Normal weight $18.5-24.9 \mathrm{~kg} / \mathrm{m}^{2}$. c. Overweight $25.0-29.9 \mathrm{~kg} / \mathrm{m}^{2}$.

d. Obese $\geq 30.0 \mathrm{~kg} / \mathrm{m}^{2}$.

\subsubsection{Section $B$}

Answer to questions on LBP history such as duration for $\geq 3$ months, use of physiotherapy, exercise, use of alternative medicine (acupuncture, herbal medicine, cupping), back surgery, different doctor visit, frequency of medication use, number of visitlone year, number of work leave/last year (work absence due to chronic MLBP was denoted as days of work loss and defined as the number of days of restricted routine activity or absence at workplace because of chronic MLBP occurring within the last year).

\subsubsection{Section $C$}

Focuses on back pain disability by measuring pain intensity using visual analogue scale (VAS), and disability which was assessed using Quebec back pain disability scale (QBPDS) (Appendix III).

Modified Arabic version were used in this study (Appendix IV).

The pain VAS is "a measure for pain intensity which has been widely used in diverse adult populations" [38]. The pain VAS is self-completed by the respondents. The respondents were asked to place a line perpendicular to the VAS line at the point that represents their pain intensity. The score is determined by measuring the distance millimetre $(\mathrm{mm})$ on the 10-centimeters line scores from 0-100 using a ruler. A higher score indicates greater pain intensity: no pain (0-4 $\mathrm{mm})$, mild pain (5-44 $\mathrm{mm})$, moderate pain (45-74 $\mathrm{mm})$, and severe pain (75- $100 \mathrm{~mm})$ [38].

The QBPDS is used to measures the level of functional disability. QBPDS were published by Kopec et al in 1995 and 1996. Patients were asked to answer the QBPDS according to the difficulty they found to perform the activities currently. Items represent basic daily activities that patients with back pain might perceive hard to perform. The items involved 20 questions which were classified into 6 domains of activities affected by back pain:

a) Bed/rest (items 1-3)

b) Sitting/standing (items 4-6)

c) Ambulation (items 7-9)

d) Movement (items 10-12)

e) Bending/stooping (items 13-16)

f) Handling of large/heavy objects (items 17-20).

For each item, a 6 point Likert scale $(0-5)$ to indicate the level of difficulty is used, where $0=($ not difficult at all $)$, $1=($ minimally difficult $), 2=($ somewhat difficult $), 3=($ fairly difficult), 4=(very difficult) and 5=(unable to do).

Perceived disability reported as
a) Mild 0-9
b) Moderate 10-30
c) Severe 31-75
d) Very severe (extreme) 76-100 [39].

\subsection{Limitations of the Study}

The other associated factors of disability like depression, 
anxiety, and fear avoidance not assessed in this study.

\subsection{Statistical Analysis}

The analysis of data was carried out using SPSS version 23. Number and percentage were used to express the categorical and mean \pm SD data. Anova, independent student test, chisquare test and Pearson correlation were used to confirm significance. Statistically significant reading is considered whenever the P-value was $<0.05$.

\section{Results}

A sample of 300 patients with chronic MLBP were included. The mean age of the studied sample was $49 \pm 11$ years with age range of $18-70$ years. More than $65 \%$ of the studied sample were female and $83.3 \%$ were married. The remainders belonged to other marital status (single, divorced, widow).

As to educational status, the highest percentage $(31.3 \%)$ had primary education followed by secondary education
$(25 \%)$, college degree $(16.3 \%)$, read and write $(10 \%)$ and $(17 \%)$ were illiterate.

Concerning BMI and smoking status, the results revealed that the mean BMI in the studied group was $30 \mathrm{~kg} / \mathrm{m}^{2}$. Nearly $20.7 \%$ of the patients were current smokers, $47.7 \%$ were nonsmokers, and $26.3 \%$ were ex-smokers, while the remainder were passive smoker.

Higher percentage of the patients $(58.7 \%)$ were not suffering from co-morbid illness (HT, DM, IHD,... ect). It is also important to mention that the majority of the patients $(86.3 \%)$ lived in the urban area and the remainder were from rural area.

Regarding social classes, $63.7 \%$ of the patients were belonging to social class $\mathrm{E}$ (unemployed/receiving benefits) and the remainder distributed in lower percentages to other social classes (A, B, C1, C2 and D).

As to the employment, $77.7 \%$ of the participants were not employed and $10.3 \%$ were manual workers. Almost $37 \%$ were non-manual workers, while $52.7 \%$ were housewives (Table 1).

Table 1. Socio-demographic characteristics of studied sample.

\begin{tabular}{|c|c|c|c|}
\hline \multirow{2}{*}{\multicolumn{2}{|c|}{ Age/year }} & Mean & SD \\
\hline & & 49 & 11 \\
\hline \multicolumn{2}{|l|}{$\mathrm{BMI}\left(\mathrm{kg} / \mathrm{m}^{2}\right)$} & 30 & 6 \\
\hline \multicolumn{2}{|c|}{ Socio-demographic characteristics } & No. & $\%$ \\
\hline \multirow{2}{*}{ Gender } & Male & 104 & $34.7 \%$ \\
\hline & Female & 196 & $65.3 \%$ \\
\hline \multirow{4}{*}{ Marital status } & Single & 22 & $7.3 \%$ \\
\hline & Married & 250 & $83.3 \%$ \\
\hline & Divorced & 5 & $1.7 \%$ \\
\hline & Widow & 23 & $7.7 \%$ \\
\hline \multirow{6}{*}{ Education status } & Illiterate & 51 & $17.0 \%$ \\
\hline & Read and write & 30 & $10.0 \%$ \\
\hline & Primary & 94 & $31.3 \%$ \\
\hline & Secondary & 75 & $25.0 \%$ \\
\hline & College & 49 & $16.3 \%$ \\
\hline & Higher education & 1 & $0.3 \%$ \\
\hline \multirow{4}{*}{ Smoking status } & Yes & 62 & 20.7 \\
\hline & No & 143 & 47.7 \\
\hline & Passive & 16 & 5.3 \\
\hline & Ex-smoker & 79 & 26.3 \\
\hline \multirow{2}{*}{ Residency } & Rural & 41 & $13.7 \%$ \\
\hline & Urban & 259 & $86.3 \%$ \\
\hline \multirow{2}{*}{ Comorbidity } & Yes & 124 & $41.3 \%$ \\
\hline & No & 176 & $58.7 \%$ \\
\hline \multirow{2}{*}{ Religion } & Muslim & 299 & $99.7 \%$ \\
\hline & Others & 1 & $0.3 \%$ \\
\hline \multirow{6}{*}{ Social class } & A & 8 & $2.7 \%$ \\
\hline & B & 14 & $4.7 \%$ \\
\hline & $\mathrm{C} 1$ & 26 & $8.7 \%$ \\
\hline & $\mathrm{C} 2$ & 16 & $5.3 \%$ \\
\hline & $\mathrm{D}$ & 45 & $15.0 \%$ \\
\hline & $\mathrm{E}$ & 191 & $63.7 \%$ \\
\hline \multirow{2}{*}{ Job } & Employed & 67 & $22.3 \%$ \\
\hline & Not employed & 233 & $77.7 \%$ \\
\hline \multirow{3}{*}{ Type of work } & Manual & 31 & $10.3 \%$ \\
\hline & Non-manual & 111 & $37.0 \%$ \\
\hline & House wife & 158 & $52.7 \%$ \\
\hline
\end{tabular}

BMI: body mass index, SD: standard deviation

The findings of the current study revealed that $20 \%$ of those patients had $>5$ years back pain duration, $59.3 \%$ had back pain for $1-5$ years, $9.7 \%$ had $6 \mathrm{~m}-1$ year back pain, and $11 \%$ of those with $<6$ months back pain duration. 
Regarding the level of disability according to Quebec back pain disability scale (QBPDS), 16\% of the patients had a mild level of disability, $62 \%$ had a moderate level of disability, $19.3 \%$ with a severe level of disability, and $2.7 \%$ very severe level of disability.
Regarding the modality of therapy that the patients had in the last one year, the results showed that just $16.7 \%$ of them had physiotherapy, only $6.3 \%$ practicing exercise regularly, $9.1 \%$ used alternative medicine (acupuncture, herbal medicine, cupping) and 2.7\% underwent surgery (Table 2).

Table 2. Descriptive characteristics of clinical and therapy status

\begin{tabular}{|c|c|c|c|}
\hline & & No. of patients & $\%$ \\
\hline \multirow{4}{*}{ Duration of back pain } & $<6$ months & 33 & $11.0 \%$ \\
\hline & 6 months- 1 year & 29 & $9.7 \%$ \\
\hline & $1-5$ years & 178 & $59.3 \%$ \\
\hline & $>5$ years & 60 & $20.0 \%$ \\
\hline \multirow{3}{*}{ Functional level } & Mild & 48 & $16.0 \%$ \\
\hline & Moderate & 186 & $62.0 \%$ \\
\hline & very sever & 8 & $2.7 \%$ \\
\hline \multirow{3}{*}{ Frequency of medication use } & On need & 198 & $66.0 \%$ \\
\hline & Daily & 36 & $12.0 \%$ \\
\hline & Non & 66 & $22.0 \%$ \\
\hline Use of physiotherapy & Yes & 50 & $16.7 \%$ \\
\hline Exercise & Yes & 19 & $6.3 \%$ \\
\hline Use of alternative medicine & Yes & 27 & $9.1 \%$ \\
\hline Surgery & Yes & 8 & $2.7 \%$ \\
\hline
\end{tabular}

With regards to patient's behaviours concerning physician consultation, the results demonstrated that $39.3 \%$ of the patients consulted different doctors in their private clinics. Nearly $44 \%$ sought medical help at the outpatient clinics of governmental hospitals. The results also revealed that $22 \%$ of the patients did not use any medication for their back pain, $12 \%$ used daily medication, and $66 \%$ of the patients used medication on need.
The majority of the patients $(90.3 \%)$ consulted their physicians $\leq 3$ times yearly, $8 \%$ for $>3$ times annually, and only $1.7 \%$ of them did not consult any doctor before attending the hospital. The majority of the patients (93.3\%) did not got work leave for the last year, $5 \%$ got work leave one time during the last year, $1.3 \%$ got two work leaves during the last year, and only $0.3 \%$ had three work leaves during the last year. The average duration of work leave was 5 days (Table 3).

Table 3. Descriptive characteristics of patients behaviours concerning physicians consultation, using of medication and work leave per last year.

\begin{tabular}{|c|c|c|c|}
\hline & & No. & $\%$ \\
\hline \multirow{3}{*}{ Different doctor } & Yes & 118 & $39.3 \%$ \\
\hline & No & 50 & $16.7 \%$ \\
\hline & Outpatient & 132 & $44.0 \%$ \\
\hline \multirow{3}{*}{ No. of visitlone year } & Non & 5 & $1.7 \%$ \\
\hline & $=<3$ & 271 & $90.3 \%$ \\
\hline & $>3$ & 24 & $8.0 \%$ \\
\hline \multirow{4}{*}{ Number of work leave/last year } & Non & 280 & $93.3 \%$ \\
\hline & $1 /$ year & 15 & $5.0 \%$ \\
\hline & $2 /$ year & 4 & $1.3 \%$ \\
\hline & 3/year & 1 & $0.3 \%$ \\
\hline
\end{tabular}

According to mean value of visual analogue scale (VAS) females patients reported higher significant mean VAS than males patients $(\mathrm{P}=0.01)$. Manual workers and housewives also reported significant higher level of mean VAS than nonmanual workers $(\mathrm{P}<0.05$ for all). Patients with primary school reported higher mean VAS than other educational level. Non-significant difference of VAS was reported in relation to marital status, smoking, residency, social class, comorbidities and job of the patients in term of employed or non-employed ( $\mathrm{P}>0.05$ for all) (Table 4).

(Table 5) showed that the mean of VAS was increased with increasing the duration of the disease to level of 6.1 with patients who were complaining from back pain for more than five years in comparison to those with back pain less than 5 years, but the difference did not reach the significant level $(\mathrm{P}=0.06)$. Other tested variables (patients on physiotherapy, and who did not practice exercise regularly, those who used alternative medicine and who underwent surgery) showed non-significant differences with VAS (P-value $>0.05$ ).

Data in this study revealed that there was non-significant correlation between age and VAS of the patients (P-value $\geq 0.05$ ) as seen in (Table 6).

(Table 7) showed that mean VAS was higher in patient group with $\mathrm{BMI}>30$ and there was significant correlation between VAS and BMI (P-value=0.01). 
Table 4. Mean value of VAS according to socio-demographic characteristics.

\begin{tabular}{|c|c|c|c|c|}
\hline & & Mean of Vas score & SD & P-value \\
\hline \multirow{3}{*}{ Gender } & Male & 5.47 & 1.5 & \multirow{3}{*}{0.01} \\
\hline & Female & 5.89 & 1.4 & \\
\hline & Single & 5.0 & 1.1 & \\
\hline \multirow{3}{*}{ Marital status } & Married & 5.82 & 1.5 & \multirow{3}{*}{0.09} \\
\hline & Divorced & 5.40 & 1.5 & \\
\hline & Widow & 5.78 & 1.4 & \\
\hline \multirow{6}{*}{ Education status } & Illiterate & 5.86 & 1.4 & \multirow{6}{*}{0.05} \\
\hline & Read and write & 5.67 & 1.3 & \\
\hline & Primary & 6.1 & 1.4 & \\
\hline & Secondary & 5.52 & 1.6 & \\
\hline & College & 5.35 & 1.3 & \\
\hline & Higher education & 6.0 & 0.0 & \\
\hline \multirow{4}{*}{ Smoking status } & Yes & 5.94 & 1.4 & \multirow{4}{*}{0.3} \\
\hline & No & 5.5 & 1.5 & \\
\hline & Passive & 5.88 & 1.8 & \\
\hline & Ex-smoker & 5.7 & 1.3 & \\
\hline \multirow{2}{*}{ Comorbidity } & Yes & 5.89 & 1.52 & \multirow{2}{*}{0.1} \\
\hline & No & 5.65 & 1.45 & \\
\hline \multirow{2}{*}{ Residency } & Rural & 6.1 & 1.4 & \multirow{2}{*}{0.1} \\
\hline & Urban & 5.69 & 1.4 & \\
\hline \multirow{6}{*}{ Social class } & A & 5.3 & 1.3 & \multirow{6}{*}{0.07} \\
\hline & B & 6.1 & 1.4 & \\
\hline & $\mathrm{C} 1$ & 5.8 & 1.4 & \\
\hline & $\mathrm{C} 2$ & 6.1 & 1.4 & \\
\hline & $\mathrm{D}$ & 5.35 & 1.3 & \\
\hline & $\mathrm{E}$ & 6.1 & 1.4 & \\
\hline \multirow{3}{*}{ Job } & Employed & 5.52 & 1.5 & \multirow{3}{*}{0.1} \\
\hline & Not employed & 5.81 & 1.4 & \\
\hline & Manual & 6.13 & 1.2 & \\
\hline \multirow[t]{2}{*}{ Type of work } & Non-manual & 5.2 & 1.5 & \multirow[t]{2}{*}{0.001} \\
\hline & House wife & 6.06 & 1.3 & \\
\hline
\end{tabular}

P-value: Probability value, SD: standard deviation, VAS: visual analogue scale

Table 5. Mean value of VAS according to clinical and medical therapy status.

\begin{tabular}{|c|c|c|c|c|}
\hline & & Mean of Vas score & SD & P-value \\
\hline \multirow{4}{*}{ Duration of back pain } & $<6$ months & 5.3 & 1.6 & \multirow{4}{*}{0.06} \\
\hline & 6 months- 1 year & 5.3 & 1.5 & \\
\hline & $1-5$ years & 5.7 & 1.4 & \\
\hline & $>5$ years & 6.1 & 1.5 & \\
\hline \multirow{2}{*}{ Use of physiotherapy } & Yes & 5.8 & 1.5 & \multirow{2}{*}{0.6} \\
\hline & No & 5.7 & 1.4 & \\
\hline \multirow{2}{*}{ Exercise } & Yes & 5.2 & 1.1 & \multirow{2}{*}{0.07} \\
\hline & No & 5.8 & 1.5 & \\
\hline \multirow{2}{*}{ Use of alternative medicine } & Yes & 5.9 & 1.8 & \multirow{2}{*}{0.5} \\
\hline & No & 5.7 & 1.4 & \\
\hline \multirow{2}{*}{ Surgery } & Yes & 5.9 & 1.3 & \multirow{2}{*}{0.7} \\
\hline & No & 5.7 & 1.4 & \\
\hline
\end{tabular}

P-value: probability value, VAS: visual analogue scale, SD: standard deviation

Table 6. Correlation between VAS and age.

\begin{tabular}{lllll}
\hline Age group & No. & Mean VAS & SD & P-value \\
\hline $20-40$ & 61 & 5.59 & 1.29 & 0.5 \\
$40-60$ & 180 & 5.82 & 1.46 \\
$>60$ & 59 & 5.68 & 1.73 \\
\hline
\end{tabular}

P-value: probability value VAS: visual analogue scale. SD: standard deviation 
Table 7. Correlation between VAS and BMI.

\begin{tabular}{lllll}
\hline BMI & No. & Mean VAS & SD & P-value \\
\hline $18-25$ & 38 & 5.53 & 1.52 & 0.01 \\
$25-30$ & 138 & 5.54 & 1.38 & 1.54 \\
$>30$ & 124 & 6.05 & 1.05 & \\
\hline
\end{tabular}

BMI: body mass index. P-value: probability VAS: visual analogue scale. SD: standard deviation

The finding of this study showed there was a significant association ( $\mathrm{P}$-value $\leq 0.05$ ) between the level of disability and each of age, gender, BMI, education, residency, job, type of work, and history of co- morbid illnesses (Table 8).

The study revealed that age was associated with higher level of disability, and patient with age group $\geq 60$ reported more sever level of disability $(40.7 \%)$ than younger age groups. The severe status of disability was reported more in female patients $(22.4 \%)$ than male patients $(13.5 \%)$. Similarly, the very severe status of disability reported more with female patients $(4.1 \%)$ than male patients with no reported patient.
Patients with BMI $\geq 30 \mathrm{~kg} / \mathrm{m}^{2}$ had very severe level of disability $(5.6 \%)$, in comparison to $(2.6 \%)$ in patients with BMI less than $30 \mathrm{~kg} / \mathrm{cm}^{2}$.

Patients with lower educational level reported more severe disability (illiterate $35.3 \%$, read and write $16.7 \%$, primary school 25.5\%) than higher educational level (secondary school $10.7 \%$, collage $6.1 \%$ ) respectively.

Severe disability was reported more in a rural area (29.3\%) than urban area (17.8\%), and also patients in rural area was reported a very severe level of disability $(9.8 \%)$ in comparison to urban area $(1.5 \%)$.

Table 8. Association between functional level status and socio-demographic characteristics.

\begin{tabular}{|c|c|c|c|c|c|c|c|c|c|c|c|}
\hline & & \multirow{3}{*}{ Total no. } & \multicolumn{8}{|c|}{ Functional level } & \multirow{3}{*}{ p-value } \\
\hline & & & \multicolumn{2}{|c|}{ Mild } & \multicolumn{2}{|c|}{ Moderate } & \multicolumn{2}{|c|}{ Severe } & \multicolumn{2}{|c|}{ Very severe } & \\
\hline & & & No. & $\%$ & No. & $\%$ & No. & $\%$ & No. & $\%$ & \\
\hline Age groups/ & $18-40$ & 61 & 11 & $18.0 \%$ & 40 & $65.6 \%$ & 9 & $14.8 \%$ & 1 & $1.6 \%$ & \multirow{4}{*}{0.001} \\
\hline \multirow{3}{*}{ Years } & $40-60$ & 180 & 29 & $16.1 \%$ & 122 & $67.8 \%$ & 25 & $13.9 \%$ & 4 & $2.2 \%$ & \\
\hline & $\geq 60$ & 59 & 8 & $13.6 \%$ & 24 & $40.7 \%$ & 24 & $40.7 \%$ & 3 & $5.1 \%$ & \\
\hline & $18-25$ & 38 & 10 & $26.3 \%$ & 21 & $55.3 \%$ & 6 & $15.8 \%$ & 1 & $2.6 \%$ & \\
\hline \multirow[t]{2}{*}{ BMI } & $25-30$ & 138 & 20 & $14.5 \%$ & 87 & $63.0 \%$ & 31 & $22.5 \%$ & 0 & $0.0 \%$ & \multirow[t]{2}{*}{0.05} \\
\hline & $>30$ & 124 & 18 & $14.5 \%$ & 78 & $62.9 \%$ & 21 & $16.9 \%$ & 7 & $5.6 \%$ & \\
\hline \multirow{3}{*}{ Gender } & Male & 104 & 27 & $26.0 \%$ & 63 & $60.6 \%$ & 14 & $13.5 \%$ & 0 & $0.0 \%$ & \multirow{3}{*}{0.01} \\
\hline & Female & 196 & 21 & $10.7 \%$ & 123 & $62.8 \%$ & 44 & $22.4 \%$ & 8 & $4.1 \%$ & \\
\hline & Single & 22 & 4 & $18.2 \%$ & 17 & $77.3 \%$ & 1 & $4.5 \%$ & 0 & $0.0 \%$ & \\
\hline \multirow{3}{*}{ Marital status } & Married & 250 & 42 & $16.8 \%$ & 153 & $61.2 \%$ & 48 & $19.2 \%$ & 7 & $2.8 \%$ & \multirow{3}{*}{0.3} \\
\hline & Divorced & 5 & 0 & $0.0 \%$ & 4 & $80.0 \%$ & 1 & $20.0 \%$ & 0 & $0.0 \%$ & \\
\hline & Widow & 23 & 2 & $8.7 \%$ & 12 & $52.2 \%$ & 8 & $34.8 \%$ & 1 & $4.3 \%$ & \\
\hline \multirow{7}{*}{ Education status } & Illiterate & 51 & 3 & $5.9 \%$ & 28 & $54.9 \%$ & 18 & $35.3 \%$ & 2 & $3.9 \%$ & \multirow{7}{*}{0.002} \\
\hline & Read and write & 30 & 3 & $10.0 \%$ & 21 & $70.0 \%$ & 5 & $16.7 \%$ & 1 & $3.3 \%$ & \\
\hline & Primary & 94 & 13 & $13.8 \%$ & 53 & $56.4 \%$ & 24 & $25.5 \%$ & 4 & $4.3 \%$ & \\
\hline & Secondary & 75 & 14 & $18.7 \%$ & 52 & $69.3 \%$ & 8 & $10.7 \%$ & 1 & $1.3 \%$ & \\
\hline & College & 49 & 14 & $28.6 \%$ & 32 & $65.3 \%$ & 3 & $6.1 \%$ & 0 & $0.0 \%$ & \\
\hline & Higher education & 1 & 1 & $100.0 \%$ & 0 & $0.0 \%$ & 0 & $0.0 \%$ & 0 & $0.0 \%$ & \\
\hline & Yes & 62 & 11 & $17.7 \%$ & 37 & $59.7 \%$ & 12 & $19.4 \%$ & 2 & $3.2 \%$ & \\
\hline \multirow{3}{*}{ Smoking status } & No & 143 & 28 & $19.6 \%$ & 92 & $64.3 \%$ & 19 & $13.3 \%$ & 4 & $2.8 \%$ & \multirow{3}{*}{0.3} \\
\hline & Passive & 16 & 6 & $37.5 \%$ & 4 & $25.0 \%$ & 6 & $37.5 \%$ & 0 & $0.0 \%$ & \\
\hline & Ex-smoker & 79 & 3 & $3.8 \%$ & 53 & $67.1 \%$ & 21 & $26.6 \%$ & 2 & $2.5 \%$ & \\
\hline \multirow{2}{*}{ Comorbidity } & Yes & 124 & 14 & $11.3 \%$ & 71 & $57.3 \%$ & 32 & $25.8 \%$ & 7 & $5.6 \%$ & \multirow{2}{*}{0.02} \\
\hline & No & 176 & 34 & $19.3 \%$ & 115 & $65.3 \%$ & 26 & $14.8 \%$ & 1 & $0.6 \%$ & \\
\hline \multirow{2}{*}{ Residency } & Rural & 41 & 6 & $14.6 \%$ & 19 & $46.3 \%$ & 12 & $29.3 \%$ & 4 & $9.8 \%$ & \multirow{2}{*}{0.004} \\
\hline & Urban & 259 & 42 & $16.2 \%$ & 167 & $64.5 \%$ & 46 & $17.8 \%$ & 4 & $1.5 \%$ & \\
\hline & A & 8 & 3 & $37.5 \%$ & 4 & $50.0 \%$ & 1 & $12.5 \%$ & 0 & $0.0 \%$ & \\
\hline & B & 14 & 3 & $21.4 \%$ & 8 & $57.1 \%$ & 2 & $14.3 \%$ & 1 & $7.1 \%$ & \\
\hline Soriol alos & $\mathrm{C} 1$ & 26 & 8 & $30.8 \%$ & 15 & $57.7 \%$ & 2 & $7.7 \%$ & 1 & $3.8 \%$ & 006 \\
\hline social class & $\mathrm{C} 2$ & 16 & 3 & $18.8 \%$ & 11 & $68.8 \%$ & 2 & $12.5 \%$ & 0 & $0.0 \%$ & 0.00 \\
\hline & $\mathrm{D}$ & 45 & 12 & $26.7 \%$ & 28 & $62.2 \%$ & 4 & $8.9 \%$ & 1 & $2.2 \%$ & \\
\hline & $\mathrm{E}$ & 191 & 19 & $9.9 \%$ & 120 & $62.8 \%$ & 47 & $24.6 \%$ & 5 & $2.6 \%$ & \\
\hline & Employed & 67 & 19 & $28.4 \%$ & 36 & $53.7 \%$ & 9 & $13.4 \%$ & 3 & $4.5 \%$ & 0008 \\
\hline Job & Not employed & 233 & 29 & $12.4 \%$ & 150 & $64.4 \%$ & 49 & $21.0 \%$ & 5 & $2.1 \%$ & 0.008 \\
\hline & Manual & 31 & 6 & $19.4 \%$ & 17 & $54.8 \%$ & 6 & $19.4 \%$ & 2 & $6.5 \%$ & \\
\hline Type of work & Non-manual & 111 & 28 & $25.2 \%$ & 70 & $63.1 \%$ & 12 & $10.8 \%$ & 1 & $0.9 \%$ & 0.001 \\
\hline & House wife & 158 & 14 & $8.9 \%$ & 99 & $62.7 \%$ & 40 & $25.3 \%$ & 5 & $3.2 \%$ & \\
\hline
\end{tabular}

BMI: body mass index, significant $\mathrm{P}$-value $<0.05$ 
Moderate disability (64.4\%) and severe disability (21\%) was reported in non-employed patients more than employed patients $(53.7 \%),(13.4 \%)$ respectively. While very severe disability reported more in employed than non-employed (4.5\% vas 2.1 ). In a similar fashion, housewives and manual worker reported more severe disability $(25.3 \%)$, (19.4\%) than non- manual worker $(10.8 \%)$.

Regarding associated co- morbidities other than low back pain with level of disability, the result showed that there was significant association with (P-value $=0.02)$, severe and very severe level of disability $(25.8 \%),(5.6 \%)$ reported in patients with associated comorbidity in comparison to patients with no history of comorbidity $(14.8 \%),(0.6 \%)$ respectively.

The association did not reach the significant level with other parameters (marital status, smoking and social class). In spite of some difference were reported with marital status, where the percentage of married patients with all levels of disability was higher than others subcategory of marital status but the association did not reach the significant level (P-value $=0.3)$. Patients with social class $\mathrm{D}$ and $\mathrm{E}$ show higher level of disability in comparison to other social classes but the difference also did not reach the significant level $(\mathrm{p}=0.06)$.

\section{Discussion}

The aim of this study is to find the relationship between socio- demographic characteristics and chronic mechanical low back pain disability. Low backache is a vague terminology commonly understood as pain in back or in the region of spine. In a WHO study back pain was the top most in the list of anatomical site-wise pain. Unfortunately, it is often neglected at individual as well at community level; mainly because of its non-fatal and benign nature [40]. But this problem has a huge impact on quality of life of the individuals [41]. Throughout the world, low back pain is the leading cause of activity limitation and work absence, enforcing a high economic burden on individuals, families, communities, industries, and governments [42].

LBP ranked highest in terms of Years Lost due to Disability (YLD), and sixth in terms of overall burden The Disability Adjusted Life Years (DALYs) according to a systematic review of all 291 conditions studied in the Global Burden of Disease in 2010 [43].

\subsection{Relationship of Intensity of Back Pain with Socio-demographic Characteristics}

In this study the mean age of the studied sample was $49 \pm 11$ SD, near similar mean age reported in study of Tavafian SS et al with mean age of the participants was 51.62 year [44].

Regarding intensity of back pain measured by visual analogue scale (VAS) with socio-demographic characteristic there was direct correlation with BMI. Participants with more intense LBP were more likely to be overweight or obese (Pvalue $=0.01)$. This is similar to studies done by Weiner DK et al [45] and Ng SK et al [46] which showed that high intensity pain group having a higher BMI.

This study also revealed that females reported higher significant mean VAS score than males patients (1.4 SD 5.89 vs. 1.5 SD 5.47) with (P-value=0.01). Similar finding in study done by Gouveia $\mathrm{N}$ et al shows women self-reported high level of pain intensity [47]. However, result of study done by Kim GM et al show that the VAS score was higher in male patients compared with female patients [48].

Regarding residency (rural, urban) non-significant correlation was found between intensity of back pain (VAS) and residency, this is in contrasts with result done by Williams JS et al which shows that people living in rural areas were more likely to experience back pain and at higher intensity [36]. This seems to be because of strenuous outdoor household activities (e.g. carrying water or food), undertaken by people living in such areas.

This study also shows no correlation between age and VAS (P-value $=0.5$ ). This is similar to result of study done by Wettstein $\mathrm{M}$ et al which showed that association of age with pain intensity was weak and not significant $(\mathrm{P}>0.05)$ [49]. In contrast to a study done by Weiner DK et al [45] showed that adults aged 70-79 years reported more back pain intensity.

This study showed non-significant correlation of intensity of chronic back with smoking (P-value 0.3), this contrasted with a study by Williams JS et al which showed that being a current smoker was statistically significant in association with higher back pain intensity [36]. This may be explained by the fact that higher number of patients in this study were females and non-smoker.

Non-significant differences in VAS were reported in relation to job of the patients in term of being employed or nonemployed ( $>0.05$ for all). Similar results were reported in a study done by Doualla M et al in sub-Saharan in Africa [50].

The findings of this study showed no correlation was founded between pain intensity (VAS) and associated comorbidities (P-value $=0.1$ ), in contrast to study done by Williams JS et al which showed that having multiple chronic conditions, were statistically significantly associated with higher back pain intensity [36].

\subsection{Relationship Between Disability and Socio-demographic Characteristics}

The current study revealed that age was associated with higher level of disability ( $\mathrm{P}$-value=0.001) and patient with age group $\geq 60$ reported more sever level of disability $(40.7 \%)$ than younger age groups. This result was similar to those of Williams JS et al [36], Kortor NJ et al [51], Mohamed RA et al [52] and Mahrous OA et al [53], where degree of disability increased with increasing age.

This study showed that the severity status of disability was reported more in female patients $(22.4 \%)$ than male patients $(13.5 \%)$. This result was similar to studies done by Williams JS et al [36] and Weiner DK et al [45] whose results showed more females in the high disability group than males. Shiri et al stated that the risk for LBP is higher among women due to the stress of hormonal changes, gynaecological problems, 
and child birth [54]. However, another study done by Mohamed RA et al showed more disability among males. This may be related to the culture of the rural areas where the study sample was taken and the fact that males were the main provider of their families with increased responsibilities and so more susceptible to work stressors [52].

Regarding educational level This study shows significant correlation of educational level with chronic back pain disability with (P-value 0.002), and Patients with lower educational level reported more severe disability than higher educational level, this is Similar to result of Williams JS et al [36], Doualla M et al [50] and Hurwitz EL et al [55] which showed a higher level of disability in Non-high school graduates. However, a study done by Kortor NJ et al [51] showed that Patients with tertiary level of education were more affected than those with primary and secondary level of education. This differs from findings reported by previous authors that observed higher prevalence ratio of disability among the less educated patients.

This study showed that Severe and very severe level of disability was reported more in a rural area than urban area (Pvalue $=0.004)$. This is in contrast to a study by Mohamed RA et al which found more disability in patients from urban areas [52]. This may be explained by the fact that more strenuous and heavy working job carried by people from rural area.

Regarding the association of BMI with chronic back pain disability, this study showed significant correlation between BMI and degree of disability in chronic back pain (Pvalue $=0.05$ ). Patients with $B M I \geq 30$ had very severe level of disability in comparison to patients with BMI less than 30 . Similar results from a study by Hurwitz EL et al showed that participant with weight above the 50th percentile, were relatively more likely to have chronic back disability [55].

This study revealed a non- significant correlation between smoking and disability level ( $\mathrm{P}$-value $=0.3)$. This is in contrast to a study done by Fujii $\mathrm{T}$ et al which showed that smoking was associated with chronic disabling LBP [56].

The present study revealed that significant correlation was found between the degree of disability and type of work and that housewives and manual workers reported more severe disability than non- manual workers (P-value $=0.001)$ as they are more susceptible to mechanical load and abnormal posture like bending and lifting heavy objects. This is in contrast to the study of Williams JS et al where people with low physical activities had more disability compared to those with higher physical activities, and those who were working had less disabilities compared to those who never worked [36].

Also this study showed that significant correlation is found between employment and chronic back pain disability (Pvalue $=0.008$ ). Moderate disability and severe disability were reported in unemployed patients more than employed patients. Similar result were reported by Hurwitz EL et al study showed unemployed were relatively more likely to have chronic back disability [55]. we believed that this is due to psychosocial stresses of being unemployed; However, this was in contrast to Kortor NJ et al study which showed there was no significant relationship between employment status and level of disability [51].

This study showed statistically significant correlation of chronic low back pain disability and non-back pain comorbidity (HT, DM, IHD, CVD) with (P-value $=0.02)$, and comorbid conditions associated with higher level of disability in chronic LBP. Similar results by Weiner DK et al showed comorbid conditions associated with greater severity of LBP [45], and Fujii Tet al showed chronic diseases were associated with disability due to lower back disorders [56].

Although in spite of some differences reported with marital status, where the percentage of married patients with all levels of disability was higher than others subcategories. The association did not reach the significant level (Pvalue $=0.3$ ). Similar result reported by Mohamed RA et al [52], and Mahrous OA et al [53], who showed significant correlation among marital status and degree of disability and that disability increased between married patients. This may be due to increased psychosocial stressors of marriage, and may be attributed to the fact that daily activities of married persons require repeated bending, lifting and pulling movement of the spine which may aggravate low back pain. This was in contrast to the findings of study done by Doualla $M$ et al [50], and Hurwitz EL et al [55], which indicated that the disability was significantly higher in the widowed and never married when compared to the married.

The finding of this study revealed that Patients with social class D and E show higher level of disability in comparison to other social classes but the difference also did not reach the significant level ( $p$ - value=0.06). Study by Hagen KB et al found low socio-economic status was significantly associated with the incidence of non-inflammatory back pain disability. The incidence was increased 10.5-fold for unskilled male workers, and 7.2-fold for unskilled female workers as compared with the highest social class [57].

\section{Conclusions}

According to the finding in this study disability in chronic MLBP influenced by different socio-demographic factors. Significant associations were found between the level of disability and each of age, gender, BMI, education, residency, job and type of work. Chronic LBP intensity was associated with female gender, primary school education, manual workers and housewives, higher BMI, and disease duration of more than five years.

Disability in patients with chronic MLBP is a common health problem in our environment. Accordingly, more awareness should be raised about the magnitude of the problem and about the risk factors for LBP. In addition, LBP prevention programs among patients should focus on improved working environment, physical exercise and decreased risk factors of LBP. Adoption of healthy lifestyle, Weight restriction programs should be initiated in governmental and non-governmental institutes. National wide sized studies on disability of low back pain among adults must be supported. 


\section{Appendix}

\section{Appendix I: Data Collecting Questioner}

Section A: Socio-demographic data

\begin{tabular}{|c|c|c|c|c|}
\hline $\begin{array}{l}\text { - Name: } \\
\text { - Marital status: }\end{array}$ & - Age: & - Gender: & & \\
\hline $\begin{array}{l}\text { Married } \\
\text { - Occupation: }\end{array}$ & Unmarried & Divorced & Widow & \\
\hline $\begin{array}{l}\text { Employed } \\
\text { - Residency: }\end{array}$ & Unemployed & & & \\
\hline $\begin{array}{l}\text { Urban } \\
\text { - Type of work: }\end{array}$ & Rural & & & \\
\hline $\begin{array}{l}\text { Manual } \\
\text { - Educational level: }\end{array}$ & Non manual & Housewife & & \\
\hline $\begin{array}{l}\text { Illiterate } \\
\text { - Social class: }\end{array}$ & Read and write & Primary school & Secondary school & College and Higher education \\
\hline $\begin{array}{l}\text { A } \\
\text { - Smoking: }\end{array}$ & B & $\mathrm{C}$ & $\mathrm{D}$ & E \\
\hline $\begin{array}{l}\text { Current smoker } \\
\text { - BMI: } \\
\text { - Chronic illness: }\end{array}$ & Non- smoker & X-smoker & Passive smoker & \\
\hline
\end{tabular}

\section{Section B:}

- Back pain duration:

- Frequency of medication use:

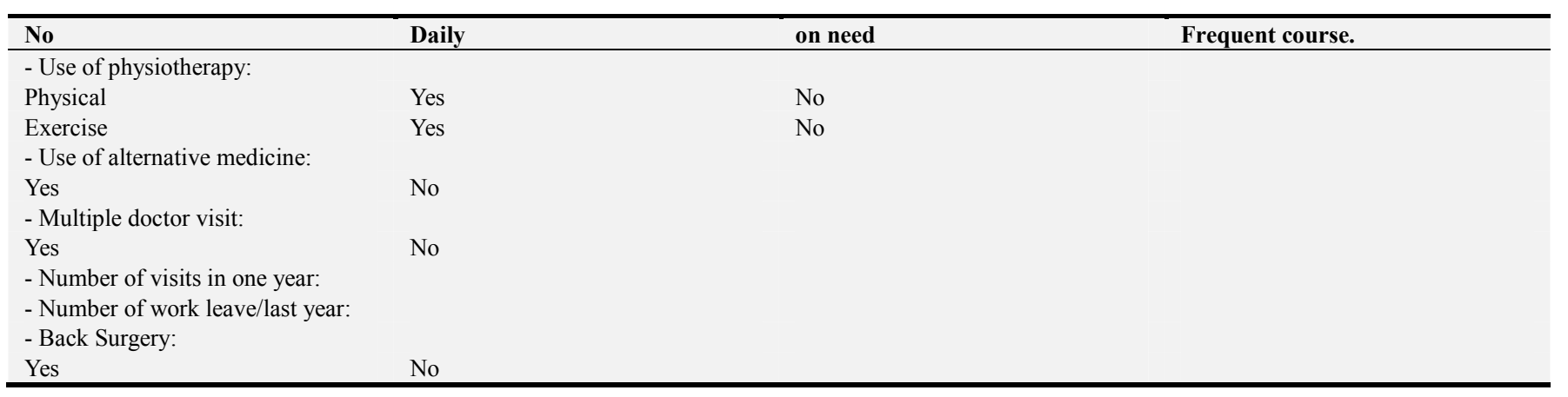

Section $C$

- VAS score:

- Functional level:

\section{Appendix II: Classification of Social Grade}

\begin{tabular}{|c|c|c|}
\hline Social Grade & Social Status & Chief income earner's profession \\
\hline $\mathbf{A}$ & Upper Middle Class & $\begin{array}{l}\text { Higher managerial, administrative } \\
\text { or professional, doctors and } \\
\text { lawyers }\end{array}$ \\
\hline $\mathbf{B}$ & Middle Class & $\begin{array}{l}\text { Intermediate managerial, } \\
\text { administrative or professional. } \\
\text { Managers and teachers }\end{array}$ \\
\hline C1 & Lower Middle Class & $\begin{array}{l}\text { Non-manual workers. Office } \\
\text { workers }\end{array}$ \\
\hline C2 & Skilled Working Class & $\begin{array}{l}\text { Skilled manual workers. Plumbers } \\
\text { and Electricians. }\end{array}$ \\
\hline D & Working Class & $\begin{array}{l}\text { Semi-skilled and unskilled manual } \\
\text { workers. Shop assistants, farm and } \\
\text { building site labourers }\end{array}$ \\
\hline E & $\begin{array}{l}\text { Unemployed/ receiving } \\
\text { benefits }\end{array}$ & $\begin{array}{l}\text { Casual workers (not in regular } \\
\text { employment) Pensioners and } \\
\text { others who depend on the state for } \\
\text { their income }\end{array}$ \\
\hline
\end{tabular}

Social grade. Downloaded in $15^{\text {th }}$ April 2019. Available from:

http://www.nrs.co.uk/nrs-print/lifestyle-and-classification-data/social-grade 


\section{Appendix III: The Quebec Back Pain Disability Scale}

People with back problems may find it difficult to perform some of their daily activities. For each activity there is a scale of 0 to 5 . Today, do you find it difficult to perform the following activities because of your back?

\begin{tabular}{l}
\hline 0 \\
\hline Get out of bed \\
Sleep through the night \\
Turnover in bed \\
Ride in a car \\
Stand up for 20- 30 minutes \\
Sit in a chair for several hours \\
Climb one flight of stairs \\
Walk a few blocks (300-400 m) \\
Walk several kilometres \\
Reach up to high shelves \\
Throw a ball \\
Run one block (about $100 \mathrm{~m})$ \\
Take food out of the refrigerator \\
Make your bed \\
Put on socks (pantyhose) \\
Bend over to clean the bathtub \\
Move a chair \\
Pull or push heavy doors \\
Carry two bags of groceries \\
Left and carry a heavy suitcase \\
\hline
\end{tabular}

Kopec, JA, Esdaile, JM, Abrahamowicz, M., Abenhaim, L, et al (1995). The Quebec Back Pain Disability Scale. Spine, 20 (3): 341-352. Davidson, M. \& Keating, J. L. (2002). A comparison of five low back disability questionnaires: Reliability and responsiveness. Physical Therapy, 82 (1): 8- 24.

\section{Appendix IV: Arabic Version of Quebec Back Pain Disability Scale}

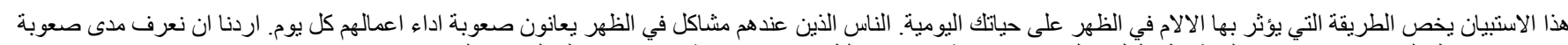

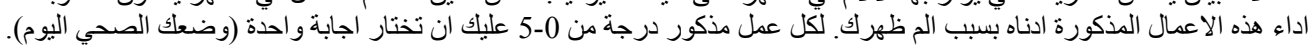

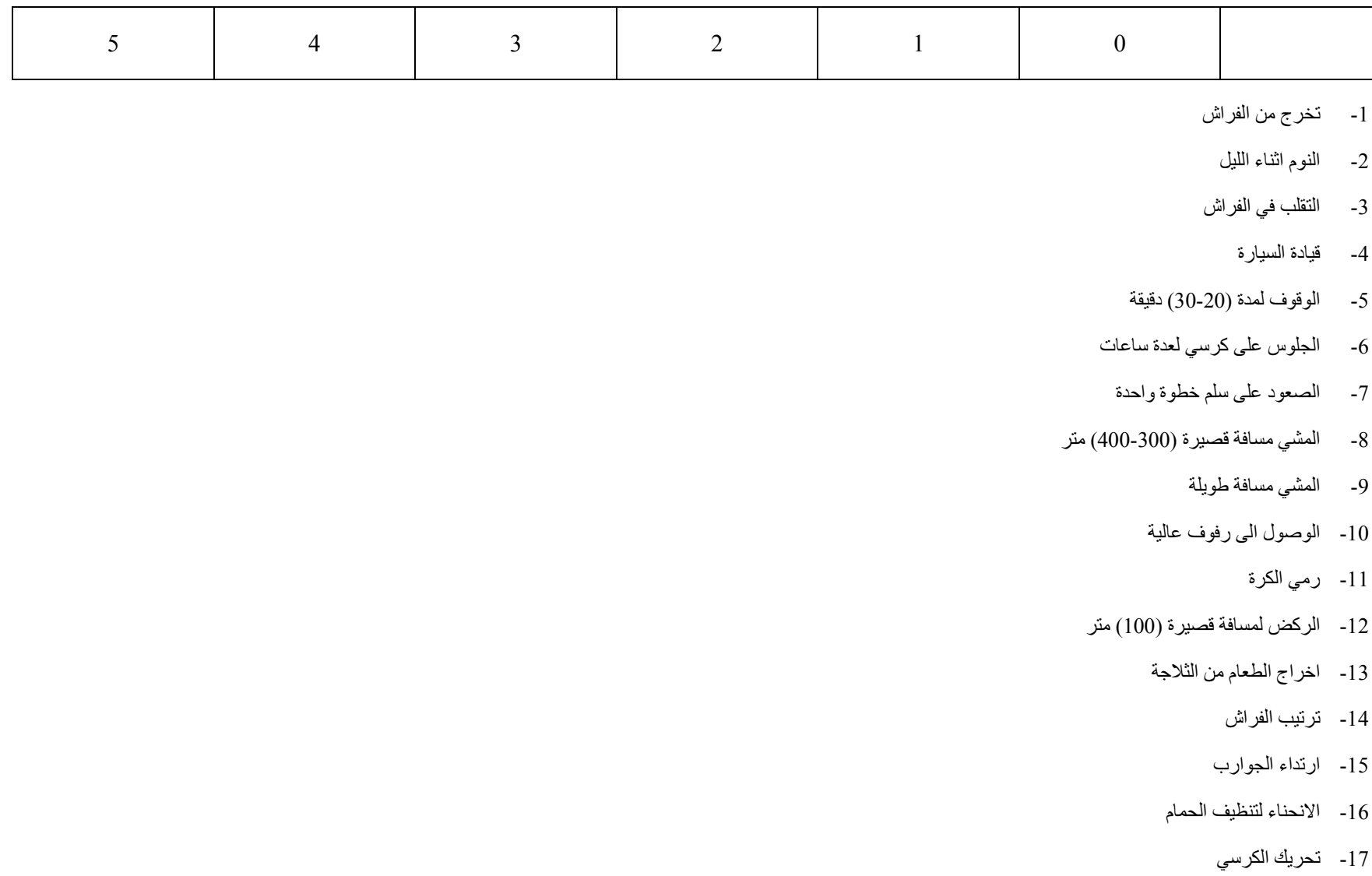


Sami Salman Shihab and Eman Qasim Khider: Correlation of Pain Intensity and Level of Disability with the Socio-demographic Characteristics in Patients with Chronic Mechanical Low Back Pain

$$
\begin{aligned}
& \text { 18- سحب ودفع ابو اب ثقيلة } \\
& \text { 19- حمل كيسين بكلنا اليدين } \\
& \text { 20- حمل حقيبة ثقيلة }
\end{aligned}
$$

Bendeddouche I, Rostom S, Bahiri R, Boudali A, et al. Translation, adaptation and validation of the Moroccan version of the Quebec Back Pain Disability Scale. Clinical rheumatology. 2012 Jun 1; 31 (6): 943-9.

\section{References}

[1] Manek NJ, MacGregor AJ. Epidemiology of back disorders: prevalence, risk factors, and prognosis. Curr Opin Rheumatol. 2005; 17 (2): 134-40.

[2] Deyo RA, Tsui-Wu YJ. Descriptive epidemiology of low back pain and its related medical care in the United States. Spine 1987; 12 (3): 264-8.

[3] Chou R. in the clinic. Low back pain. Ann Intern Med. 2014; 160: ITC 6 .

[4] Khan AA, Uddin MM, Chowdhury AH, Guha RK. Association of low back pain with common risk factors: a community based study.. Indian J Med Res. 2014; 25: 50-5.

[5] Badley EM, Rasooly I, Webster GK. Relative importance of musculoskeletal disorders as a cause of chronic health problems, disability, and health care utilization: findings from the 1990 Ontario Health Survey. J Rheumatol. 1994; 21 (3): 505-14.

[6] Nurul I, Haslinda A, Saidi M, Shamsul B, et al. Prevalence of low back pain and its risk factors among school teachers. Am J Appl Sci. 2010; 7 (5): 634-9.

[7] Deyo RA, Mirza SK, Martin BI. Back pain prevalence and visit rates: estimates from US national surveys. Spine 2006; 31 : 2724-7.

[8] Tavafian SS, Jamshidi A, Mohammad K, Montazeri A. Low back pain education and short term quality of life: a randomized trial. BMC Musculoskelet Disord.. 2007; 8 (1): 21.

[9] Vandergrift JL, Gold JE, Hanlon A, Punnett L. Physical and psychosocial ergonomic risk factors for low back pain in automobile manufacturing workers. Occup Environ Med 2012; 69 (1): $29-34$

[10] Guo HR. Working hours spent on repeated activities and prevalence of back pain. Occup Environ Med. 2002; 59 (10): $680-8$.

[11] Omokhodion FO, Umar US, Ogunnowo BE. Prevalence of low back pain among staff in a rural hospital in Nigeria. Occup Med. 2000; 50 (2): 107-10.

[12] Damian Hoy, Christopher Bain, Gail Williams, et al. A Systematic Review of the Global Prevalence of Low Back Pain. American College of Rheumatology. 2012; 64 (6), 2028-2037.

[13] Alghadir A, Anwer G. prevalence of musculoskeletal pain in construction workers in Saudi Arabia. The Scientific World Journal. 2015; 2015.

[14] Borczuk, Pierre. "An Evidence-Based Approach to the Evaluation and Treatment of Low Back Pain in the Emergency Department". Emerg Med Pract. 2013; 15 (7).

[15] Ayeni GO, Morakinyo OM, Olaniyi O, et al. Prevalence and relationship between analgesic and alcohol pain amongst craftsmen in a South-East Nigerian community. Am J Public Health Res. 2014; 2 (5-1): 45-9.

[16] Vindigni D, Walker BF, Jamison JR, et al. Low back pain risk factors in a large rural Australian Aboriginal community. An opportunity for managing co-morbidities?. Chiropr Osteopat. 2005; 13 (1): 21.

[17] Mielenz TJ, Devellis RF, Battie MC, Carey TS. Stop using the modified work APGAR to measure job satisfaction. Pain Res Treat 2011; 2011: 1-8.

[18] Arnold YL Wong, Jaro Karppinen and Dino Samartzis. Low back pain in older adults: risk factors, management options and future directions. Scoliosis and Spinal Disorders. 2017; 12 (14). 1-23.

[19] Dixit R, Low Back Pain. In: Gary F, Ralph B, Sherine G, Iain $M$ and James O. Kelley and Firestein's Textbook of Rheumatology. 10th edition, Elsevier, Philadelphia, United State. 2017; 498.

[20] Scott will J, bury DC, Miller JA. Mechanical low back pain. American family physician. 2018; 98 (7).

[21] Jancuska JM, Spivak JM, Bendo JA. Areview of symptomatic lumbosacral transitional vertebrae: Bertolottis syndrome. Int $J$ Spine Surg. 2015: 9: 42.

[22] Haroon M, Gallagher P, FitzGeraled O. Inflammatory back pain criteria perform well in subset of patients with active axial psoriatic arthritis but not among patients with established axial disease. Ann Rheum Dis. 2019; 78 (7): 1003-4.

[23] Jarvik JG, Deyo RA. Diagnostic evaluation of low back pain with emphasis on imaging. Ann Intern Med. 2002; 137 (7): 586-97.

[24] Sypert G, Arpin-Sypert EJ. Evaluation and management of the failed back syndrome. Youmans neurological surgery. Elsevier Saunders, New York. 2004: 4327-44.

[25] Resnick DK, Choudhri TF, Dailey AT, et al. Guidelines for the performance of fusion procedures for degenerative disease of the lumbar spine. Part 8: lumbar fusion for disc herniation and radiculopathy. J Neurosurg Spine. 2005; 2 (6): 673-8.

[26] Borenstein D. Mechanical low back pain - a rheumatologist's view. Nat Rev Rheumatol. 2013; 9 (11): 643.

[27] Doualla M, Aminde J, Aminde LN, Lekpa FK, et al. Factors influencing disability in patients with chronic low back pain attending a tertiary hospital in sub-Saharan Africa. BMC Musculoskelet Disord. 2019; 20 (1): 25.

[28] Al-Falahi M, Salal M, Abdul-Wahab Dh. Antibiotic treatment in patient with chronic low back pain and vertebral bone edema (modic tipe I change): a randomized clinical controlled trial of efficacy. IPMJ. 2014; 13 (3): 390-397.

[29] Al-Tamimi M, standard Discectomy versus Micro discectomy: short Term and Long Term Comparison in Treatment of Lateral Lumbar Disc Herniation. IJMS. 2016; 14 (4): 366-72. 
[30] Schoppink LE, van Tulder MW, Koes BW, Beurskens SA, et al. Reliability and validity of the Dutch adaptation of the Quebec Back Pain Disability Scale. Phys Ther. 1996; 76 (3): 268-75.

[31] Panahi R, Mohammadi B, Kazemi SS, et al. Low Back Pain, Disability and Quality of Life among University Students. International Journal of Musculoskeletal Pain Prevention. 2016; 1 (4): 173-7.

[32] Bergman ST, Herrström PE, Högström KR, et al. Chronic musculoskeletal pain, prevalence rates, and sociodemographic associations in a Swedish population study. $J$ Rheumatol. 2001; 28 (6): 1369-77.

[33] Natvig B, Bruusgaard D, Eriksen W. Localized low back pain and low back pain as part of widespread musculoskeletal pain: two different disorders? A cross-sectional population study. $J$ Rehabil Med. 2001; 33 (1): 21-5.

[34] Vos T, Allen C, Arora M, et al. Global, regional, and national incidence, prevalence, and years lived with disability for 310 diseases and injuries, 1990-2015: a systematic analysis for the Global Burden of Disease Study 2015. Lancet. 2016; 388 (10053): 1545-602.

[35] Kassebaum NJ, Arora M, Barber RM, Bhutta ZA, et al. Global, regional, and national disability-adjusted life-years (DALYs) for 315 diseases and injuries and healthy life expectancy (HALE), 1990-2015: a systematic analysis for the Global Burden of Disease Study 2015. Lancet. 2016; 388 (10053): 1603-58.

[36] Williams JS, Ng N, Peltzer K, Yawson A, et al. Risk factors and disability associated with low back pain in older adults in low-and middle-income countries. Results from the WHO study on global AGEing and adult health (SAGE). PLoS One. 2015; 10 (6): e0127880.

[37] WHO. Physical status: The use and interpretation of anthropometry. WHO Technical Report Series. Geneva: WHO; 1995.

[38] Hawker GA, Mian S, Kendzerska T, French M. Measures of adult pain: Visual analog scale for pain (vas pain), numeric rating scale for pain (nrs pain), mcgill pain questionnaire (mpq), short-form mcgill pain questionnaire (sf-mpq), chronic pain grade scale (cpgs), short form-36 bodily pain scale (sf-36 bps), and measure of intermittent and constant osteoarthritis pain (icoap). Arthritis Care Res. 2011; 63 (S11): S240-52.

[39] Smeets R, Köke A, Lin CW, Ferreira M, Demoulin C. Measures of function in low back pain/disorders: Low Back Pain Rating Scale (LBPRS), Oswestry Disability Index (ODI), Progressive Isoinertial Lifting Evaluation (PILE), Quebec Back Pain Disability Scale (QBPDS), and Roland-Morris Disability Questionnaire (RDQ). Arthritis Care Res 2011; 63 (S11): S158-73.

[40] Manchikanti L, Singh V, Datta S, Cohen SP, et al. American society of interventional pain physicians. Comprehensive review of epidemiology, scope, and impact of spinal pain. Pain Physician 2009; 12: 35-70.

[41] Montazeri A, Mousavi SJ. Quality of life and low back pain. Handbook of disease burdens and quality of life measures. 2010; 3979-94.

[42] Rubin DI. Epidemiology and risk factors for spine pain. Neurol Clin 2007; 25: 353-71.
[43] Hoy D, March L, Brooks P, et al. The global burden of low back pain: Estimates from the global burden of disease 2010 study. Ann Rheum Dis 2014; 73: 968-74.

[44] Tavafian SS, Jamshidi AR, Shah mohammadi S. Effectiveness of Training Programs on Functional Disability in Female Patients with Low Back Pain. International Journal of Musculoskeletal Pain Prevention. 2016; 1 (4): 179-83.

[45] Weiner DK, Haggerty CL, Kritchevsky SB, et al. How does low back pain impact physical function in independent, wellfunctioning older adults? Evidence from the Health $\mathrm{ABC}$ Cohort and implications for the future. Pain Med. 2003; 4 (4): 311-20.

[46] Ng SK, Cicuttini FM, Davis SR, et al. Poor general health and lower levels of vitality are associated with persistent, highintensity low back pain and disability in community-based women: a prospective cohort study. Maturitas. 2018; 113: 7-12.

[47] Gouveia N, Rodrigues A, Eusébio M, et al. Prevalence and social burden of active chronic low back pain in the adult Portuguese population: results from a national survey. Rheumatol Int. 2016; 36 (2): 183-97.

[48] Kim GM, Yi CH, Cynn HS. Factors influencing disability due to low back pain using the Oswestry Disability Questionnaire and the Quebec Back Pain Disability Scale. Physiother Res Int. 2015.

[49] Wettstein M, Eich W, Bieber C, Tesarz J. Pain intensity, disability, and quality of life in patients with chronic low Back pain: does age matter?. Pain Manag. 2018; 20 (3): 464-75.

[50] Doualla M, Aminde J, Aminde LN, et al. Factors influencing disability in patients with chronic low back pain attending a tertiary hospital in sub-Saharan Africa. BMC Musculoskelet Disord. 2019; 20 (1): 25.

[51] Kortor NJ, Iyor FT, Yongu WT, et al. Disability in adult patients with chronic low back pain in a north central Nigerian hospital. Nigerian Journal of Orthopedics and Trauma. 2018; 17 (2): 81.

[52] Mohamed RA, AL-Disoky S, El-Ghoul YM, Heissam KS. Prevalence of low Back pain and its effect on quality of life among patients attending Abokhalefa center, Ismailia governorate. Med J Cairo Univ. 2015; 83 (1): 385-94.

[53] Mahrous OA, Shaheen HM, Hadhoud MM, Ahmed AF. Low back pain among attendants to a Family Health Center in ElDakahlia governorate, Egypt. Menoufia Medical Journal. 2017; 30 (1): 28.

[54] Shiri R, Solovieva S, Husgafvel-Pursiainen K, et al. The association between obesity and the prevalence of low back pain in young adults: the Cardiovascular Risk in Young Finns Study. Am J Epidemiol. 2008; 167 (9): 1110-9.

[55] Hurwitz EL, Morgenstern H. Correlates of back problems and back-related disability in the United States. J Clin Epidemiol. 1997; 50 (6): 669-81.

[56] Fujii T, Matsudaira K. Prevalence of low back pain and factors associated with chronic disabling back pain in Japan. Eur Spine J. 2013; 22 (2): 432-8.

[57] Hagen KB, Holte HH, Tambs K, Bjerkedal T. Socioeconomic factors and disability retirement from back pain: a 1983-1993 population-based prospective study in Norway. Spine. 2000; 25 (19): 2480-7. 